\title{
Inhibition of cyclophilin D by cyclosporin A promotes retinal ganglion cell survival by preventing mitochondrial alteration in ischemic injury
}

\author{
SY Kim ${ }^{1,4}$, MS Shim ${ }^{1,4}$, K-Y Kim², RN Weinreb ${ }^{1}$, LA Wheeler ${ }^{3}$ and W-K Ju*,1
}

Cyclosporin A (CsA) inhibits the opening of the mitochondrial permeability transition pore (MPTP) by interacting with cyclophilin D (CypD) and ameliorates neuronal cell death in the central nervous system against ischemic injury. However, the molecular mechanisms underlying CypD/MPTP opening-mediated cell death in ischemic retinal injury induced by acute intraocular pressure (IOP) elevation remain unknown. We observed the first direct evidence that acute IOP elevation significantly upregulated CypD protein expression in ischemic retina at $12 \mathrm{~h}$. However, CsA prevented the upregulation of CypD protein expression and promoted retinal ganglion cell (RGC) survival against ischemic injury. Moreover, CsA blocked apoptotic cell death by decreasing cleaved caspase-3 protein expression in ischemic retina. Of interest, although the expression level of $\mathrm{Bcl}-\mathrm{xL}$ protein did not show a significant change in ischemic retina treated with vehicle or CsA at $12 \mathrm{~h}$, ischemic damage induced the reduction of Bcl-xL immunoreactivity in RGCs. More importantly, CsA preserved Bcl-xL immunoreactivity in RGCs of ischemic retina. In parallel, acute IOP elevation significantly increased phosphorylated Bad (pBad) at Ser112 protein expression in ischemic retina at $12 \mathrm{~h}$. However, CsA significantly preserved pBad protein expression in ischemic retina. Finally, acute IOP elevation significantly increased mitochondrial transcription factor A (Tfam) protein expression in ischemic retina at $12 \mathrm{~h}$. However, CsA significantly preserved Tfam protein expression in ischemic retina. Studies on mitochondrial DNA (mtDNA) content in ischemic retina showed that there were no statistically significant differences in mtDNA content among control and ischemic groups treated with vehicle or CsA. Therefore, these results provide evidence that the activation of CypD-mediated MPTP opening is associated with the apoptotic pathway and the mitochondrial alteration in RGC death of ischemic retinal injury. On the basis of these observations, our findings suggest that CsA-mediated CypD inhibition may provide a promising therapeutic potential for protecting RGCs against ischemic injury-mediated mitochondrial dysfunction.

Cell Death and Disease (2014) 5, e1105; doi:10.1038/cddis.2014.80; published online 6 March 2014

Subject Category: Neuroscience

Elevated intraocular pressure (IOP) is an important risk factor for retinal ganglion cell (RGC) death and optic nerve (ON) degeneration in retinal ischemia and glaucoma. ${ }^{1}$ It has been reported that blockade of mitochondrial permeability transition pore (MPTP) protects neuronal cells against ischemic injury. ${ }^{2-5}$ The MPTP opening leads to the loss of mitochondrial membrane potential, mitochondrial swelling, rupture of the outer mitochondrial membrane and the release of cytochrome $c^{6,7}$ Recently, MPTP-mediated neuronal cell death has been implicated as an important pathophysiological mechanism for mitochondrial dysfunction in ischemic retinal injury. ${ }^{3,8}$ However, the molecular mechanisms underlying MPTPmediated cell death in ischemic retinal injury induced by acute IOP elevation remain unclear.
The mitochondrial matrix-specific protein cyclophilin D (CypD) is an essential structural component of the MPTP with the voltage-dependent anion channel of the outer membrane and the adenine nucleotide translocase of the inner membrane of mitochondria. ${ }^{9-13}$ CypD is a peptidylprolyl cis-trans isomerase that has a critical role in the MPTP opening and subsequently regulates cell death by calcium-mediated activation. ${ }^{12-14}$ Mice lacking CypD show greater reduction of infarct size in brain and heart against ischemic injury. ${ }^{5,15,16}$ In contrast, increased level of CypD in the mitochondria results in greater vulnerability to MPTP in neuronal cells, as well as leads to impairment of mitochondrial membrane potential and excessive generation of reactive oxygen species (ROS) following focal cerebral ischemia in rats. ${ }^{17,18}$

\footnotetext{
${ }^{1}$ Laboratory for Optic Nerve Biology, Department of Ophthalmology, Hamilton Glaucoma Center, University of California San Diego, La Jolla, CA, USA; ${ }^{2}$ Center for Research on Biological Systems, National Center for Microscopy and Imaging Research and Department of Neuroscience, University of California San Diego, La Jolla, CA, USA and ${ }^{3}$ Department of Biological Sciences, Allergan Inc., Irvine, CA, USA

${ }^{*}$ Corresponding author: W-K Ju, Laboratory for Optic Nerve Biology, Department of Ophthalmology, Hamilton Glaucoma Center, University of California San Diego, 9415 Campus Point Drive, La Jolla, CA 92037, USA. Tel: +1 858246 0452; Fax: + 1858822 4717; E-mail: danielju @ glaucoma.ucsd.edu

${ }^{4}$ These authors contributed equally to this work.

Keywords: cyclosporin A; retinal ischemia; retinal ganglion cell; cyclophilin D; mitochondrial DNA; mitochondrial transcription factor A

Abbreviations: Akt, protein kinase/Akt; CNS, central nervous system; CypD, cyclophilin D; CsA, cyclosporin A; GCL, ganglion cell layer; GFAP, glial fibrillary acidic protein; INL, inner nuclear layer; IOP, intraocular pressure; IPL, inner plexiform layer; mtDNA, mitochondrial DNA; MPTP, mitochondrial permeability transition pore; ON, optic nerve; ONL, outer nuclear layer; pAkt, phosphorylated Akt; pBad, phosphorylated Bad; PI3K, phosphatidyl inositol-3-kinase; RGC, retinal ganglion cell; Tfam, mitochondrial transcription factor $\mathrm{A}$

Received 27.11.13; revised 22.1.14; accepted 30.1.14; Edited by A Verkhratsky
} 
Mitochondrial transcription factor A (Tfam, also as known as mtTFA), a nucleus-encoded DNA-binding protein in the mitochondria, has an important role in mitochondrial gene expression and mtDNA maintenance. ${ }^{19-21}$ Mice lacking Tfam have impaired mtDNA transcription and loss of mtDNA leads to bioenergetic dysfunction and embryonic lethality. ${ }^{19}$ In contrast, overexpression of Tfam mediates delayed neuronal death following transient forebrain ischemia in mice, and neonatal hypoxic-ischemic brain injury rapidly increased Tfam protein expression in a rat model. ${ }^{22-24}$ This suggests that these responses may support endogenous repair mechanisms for mtDNA damage following hypoxic-ischemic brain injury. ${ }^{23}$ Of note, acute IOP elevation significantly increased Tfam protein expression in the early neurodegeneration of ischemic rat retina, ${ }^{25}$ collectively suggesting that these responses may reflect endogenous repair mechanisms against elevated IOP-induced mitochondrial alteration in ischemic injury.

Cyclosporin A (CsA), an immunosuppressant, interacts with CypD and therefore inhibits the MPTP, decreasing sensitivity to calcium ions. ${ }^{26,27}$ In the central nervous system (CNS), CsA is neuroprotective on neuronal cells by decreasing brain infarct size, ameliorating neuronal dysfunction or preventing mitochondrial dysfunction in ischemic brain injury, ${ }^{26,28-30}$ as well as ameliorates mitochondrial dysfunction and neuronal damage in experimental traumatic brain injury. ${ }^{31,32}$ Furthermore, growing evidence indicates that CsA increases RGC survival and axonal regeneration into peripheral nerve autografted onto the cut ON of F344 rats, as well as delays axonal degeneration and mitochondrial swelling in the
ON explants of C57BL/WId ${ }^{s}$ mice. ${ }^{14,33}$ Although CsAmediated blockade of MPTP opening has been implicated as a potential target for therapeutic intervention in ischemic injury, it remains unknown whether CsA protects RGCs against ischemic retinal injury.

In the current study, we determined whether CsA promotes RGC survival and blocks the upregulation of CypD protein expression, and whether it prevents apoptotic pathway and alters Tfam protein expression and mtDNA content in ischemic retinal injury.

\section{Results}

The effect of CsA in IOP and body weight. We began either vehicle or CsA treatment daily until 1 day before the induction of transient retinal ischemia and then continued vehicle or CsA treatment daily for 2 weeks (Figure 1a). Transient retinal ischemia was induced by acute IOP elevation to $77.3 \pm 4.6 \mathrm{~mm} \mathrm{Hg}$ in mice treated with vehicle and $84.1 \pm 6.6 \mathrm{~mm} \mathrm{Hg}$ in mice treated with CsA for $50 \mathrm{~min}$ during anterior chamber perfusion with saline $(n=30$ mice per group; Figure $1 \mathrm{~b}$ ). The mean IOP of non-ischemic contralateral control eyes was $10.8 \pm 1.8 \mathrm{~mm} \mathrm{Hg} \quad(n=30$ mice; Figure 1b). In addition, no difference was found in body weight between vehicle- and CsA-treated mice during experimental period ( $n=30$ mice; Figure $1 \mathrm{~b}$ ).

CsA promotes RGC survival in ischemic retina. We determined whether CsA promotes RGC survival in ischemic retina using whole-mount immunohistochemistry using

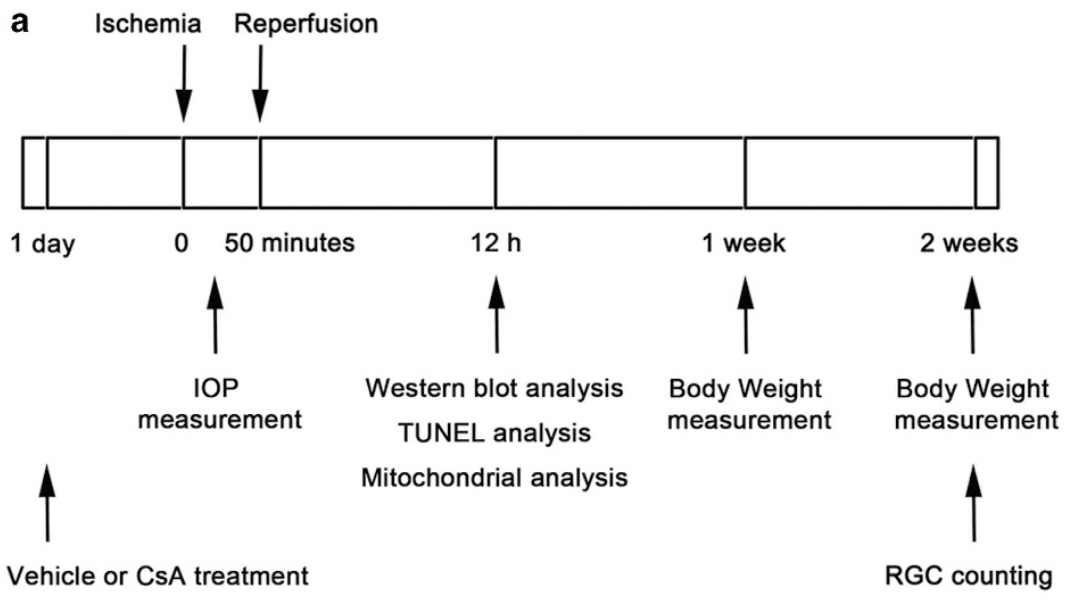

b
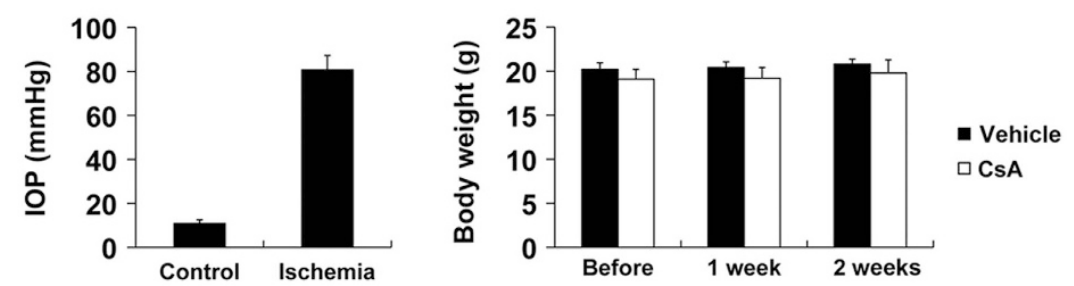

Figure 1 CsA treatment and induction of transient retinal ischemia. (a) Diagram for CsA treatment before and after ischemic injury. Vehicle or CsA treatment was begun daily until 1 day before the induction of transient retinal ischemia and continued for 2 weeks. (b) IOP elevation in the mouse eyes and body weight following transient retinal ischemic injury 
antibody raised against Brn3a, a marker for RGCs. Mean RGC density per retina for each group is presented in Table 1. Non-ischemic control mouse retina had an average of $3440 \pm 265$ RGCs in the central, $3126 \pm 385$ RGCs in the middle and $1974 \pm 236$ RGCs in the peripheral areas $(n=7$ retinas) (Figures $2 a$ and $b$ and Table 1 ). In comparison with vehicle-treated non-ischemic control retina, vehicle-treated ischemic retina showed about $32 \%$ loss of of $\operatorname{RGC}(P<0.05$; Figures $2 a$ and $b$ and Table 1). In contrast, CsA significantly promoted RGC survival by an approximate $21 \%$ compared with vehicle-treated ischemic retina $(P<0.01$; Figures $2 \mathrm{a}$ and $\mathrm{b}$; Table 1). However, there were no significant difference in RGC survival between vehicle- and CsA-treated control mice (Figure 2b and Table 1).

CsA prevents the upregulation of CypD and GFAP protein expression in ischemic retina. To determine whether CsA treatment prevents upregulation of glial fibrillary acidic protein (GFAP) and CypD protein expression, we performed western blot analysis using antibodies raised against GFAP and CypD. We observed that increase of CypD protein expression was maximal $12 \mathrm{~h}$ later by $1.54 \pm 0.39$-fold in ischemic retina compared with vehicletreated non-ischemic control retina $(P<0.05$; Figure 3a). The relative quantity of CypD protein expression was less at $24 \mathrm{~h}$ by $1.43 \pm 0.18$-fold than at $12 \mathrm{~h}$ after ischemia-reperfusion. Intriguingly, CsA treatment significantly decreased GFAP and CypD protein expression in ischemic retina at $12 \mathrm{~h}$ by $0.69 \pm 0.18-$ and $0.68 \pm 0.05$-fold compared with vehicletreated ischemic retina, respectively $(P<0.05$; Figure $3 \mathrm{~b})$. We next determined the cellular distribution of CypD protein expression in ischemic retina (Figures $3 c-e)$. In comparison with vehicle-treated non-ischemic control retina (Figure $3 c$ ), vehicle-treated ischemic retina showed the increase of CypD immunoreactivity in the outer plexiform layer (OPL), inner nuclear layer (INL), inner plexiform layer (IPL) and ganglion cell layer (GCL). Interestingly, we found that CypD immunoreactivity increased in Müller cells in the inner retina as well as in RGCs in the GCL (Figure 3d). However, CsA treatment decreased CypD immunoreactivity in the inner layer of ischemic retina (Figure $3 e$ ).

CsA blocks caspase-3-mediated apoptotic pathway in ischemic retina. To determine whether CsA treatment

Table 1 Effect of CsA on RGC survival in the central, middle and peripheral retinas at 2 weeks after ischemia-reperfusion

\begin{tabular}{lccc}
\hline \multicolumn{4}{c}{ RGC density per retina (RGCs per $\mathbf{m m}^{2}$ ) } \\
\hline Treatment & Central & Middle & Peripheral \\
\hline Control-vehicle & $3440 \pm 265$ & $3126 \pm 385$ & $1974 \pm 236$ \\
Ischemia-vehicle & $2649 \pm 106^{\mathrm{a}}$ & $2237 \pm 376^{\mathrm{a}}$ & $1458 \pm 210^{\mathrm{a}}$ \\
Ischemia-CsA & $3196 \pm 321^{\mathrm{b}}$ & $2999 \pm 348^{\mathrm{b}}$ & $1931 \pm 182^{\mathrm{b}}$ \\
Control-CsA & $3418 \pm 473$ & $3005 \pm 399$ & $1771 \pm 390$ \\
\hline
\end{tabular}

Data are expressed as the mean \pm S.D. Comparison of three experimental conditions was evaluated using the one-way analysis of variance and the Bonferroni $t$-test.

a Significant at $P<0.01$ compared with vehicle-treated non-ischemic contralateral control retina ( $n=7$ retinal flat mounts per group).

bignificant at $P<0.05$ compared with vehicle-treated ischemic retina prevents apoptotic cell death in ischemic retina, we performed TUNEL staining. There were no TUNEL-positive cells in the retina of vehicle-treated non-ischemic control mice (Figure 4a). However, vehicle-treated ischemic retina showed TUNEL-positive apoptotic cell death in the INL $(8 \pm 5$ per $200 \mu \mathrm{m})$ and GCL $(24 \pm 5$ per $200 \mu \mathrm{m})$ at $12 \mathrm{~h}$ (Figures $4 \mathrm{~b}$ and d). Higher magnification clearly showed that TUNELpositive apoptotic bodies were correlated with the nucleus of dying cells in the GCL of vehicle-treated ischemic retina (Supplementary Figure 1). In contrast, there were no TUNELpositive cells in CsA-treated ischemic retina (Figures $4 \mathrm{c}$ and d). To further confirm the CsA-mediated blockade of apoptotic cell death in ischemic retina, we also performed western blot analysis using an antibody raised against caspase-3 (cleaved form). In comparison with vehicle-treated nonischemic control retina, the cleaved caspase-3 protein expression was significantly increased from $6 \mathrm{~h}$, and peaked at $24 \mathrm{~h}$ by $33.25 \pm 2.37$-fold in vehicle-treated ischemic retina $(P<0.01$; Supplementary Figure 2). In comparison with vehicle-treated non-ischemic control retina (Figure 4e), vehicle-treated ischemic retina showed a significant induction of cleaved caspase-3 protein expression at $12 \mathrm{~h}$ by $7.61 \pm 1.79$-fold compared with vehicle-treated control retina (Figure 4e). However, CsA treatment significantly reduced cleaved caspase-3 protein expression in ischemic retina at $12 \mathrm{~h}$ by $3.33 \pm 1.08$-fold (Figure 4e). Interestingly, CsA treatment also showed a significant induction of cleaved caspase- 3 protein expression at $12 \mathrm{~h}$ by $2.50 \pm 0.79$-fold in non-ischemic control retina (Figure $4 \mathrm{e}$ ). Although our findings demonstrated the induction of cleaved caspase-3 protein expression from the whole retinal extracts of the CsA-treated control or ischemic groups, we cannot exclude a small induction of apoptotic cell death that was not detected by our TUNEL technique.

CsA modulates $\mathrm{Bcl}-\mathrm{xL}$ and $\mathrm{pBad}$ protein expression in ischemic retina. To determine whether CsA modulates apoptotic pathway in ischemic retina, we performed western blot analysis using antibodies raised against $\mathrm{Bcl}-2, \mathrm{Bcl}-\mathrm{xL}$ and phosphorylated Bad (pBad) at Ser112. In comparison with vehicle-treated non-ischemic control retina, $\mathrm{Bcl}-\mathrm{xL}$ protein expression was slightly decreased in vehicle-treated ischemic retina at $12 \mathrm{~h}$; however, there was no statistically significant difference (Figure 5a). Furthermore, CsA treatment showed no differences in ischemic retina at $12 \mathrm{~h}$ compared with vehicle-treated ischemic retina (Figure 5a). In comparison with vehicle-treated non-ischemic control retina, pBad protein expression was significantly increased by $10.9 \pm 3.7$-fold in ischemic retina at $12 \mathrm{~h} \quad(P<0.05$; Figure 5). In contrast, CsA treatment significantly decreased pBad protein expression by $4.28 \pm 2.23$-fold in ischemic retina $(P<0.05$; Figure 5$)$. There was no difference in $\mathrm{pBad}$ protein expression between vehicle- and CsA-treated nonischemic control retina (Figure $5 \mathrm{a}$ ). We next determined the cellular distribution of $\mathrm{Bcl}-\mathrm{xL}$ protein expression in ischemic retina (Figures $5 b-d$ ). In vehicle-treated non-ischemic control retina, we observed that $\mathrm{Bcl}-\mathrm{xL}$ immunoreactivity was localized in RGCs of the GCL as well as in the OPL, INL and IPL (Figure 5b). Interestingly, vehicle-treated ischemic retina showed less $\mathrm{Bcl}-\mathrm{xL}$ immunoreactivity in RGCs of the 


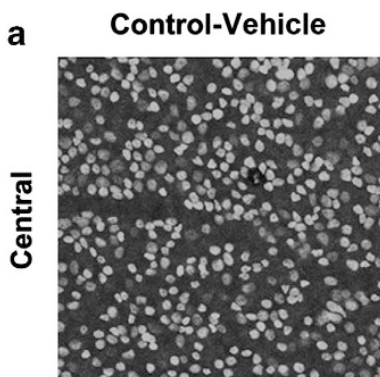

Ischemia-Vehicle
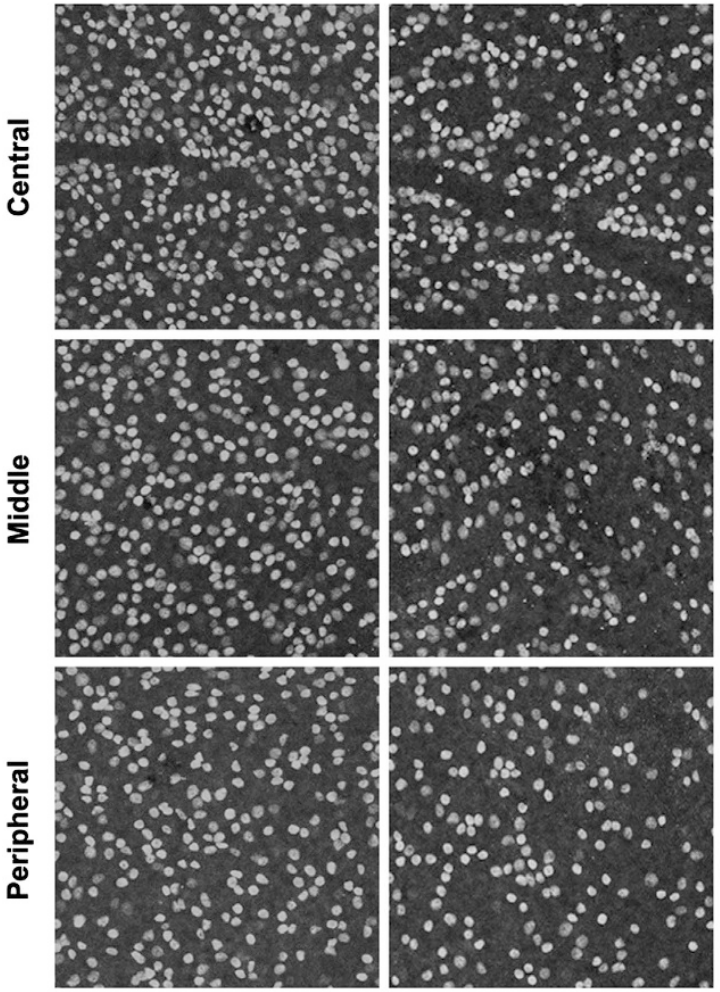

b

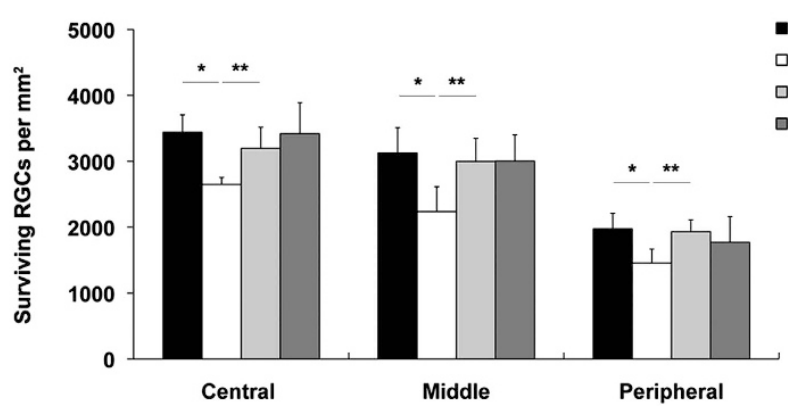

Ischemia-CsA
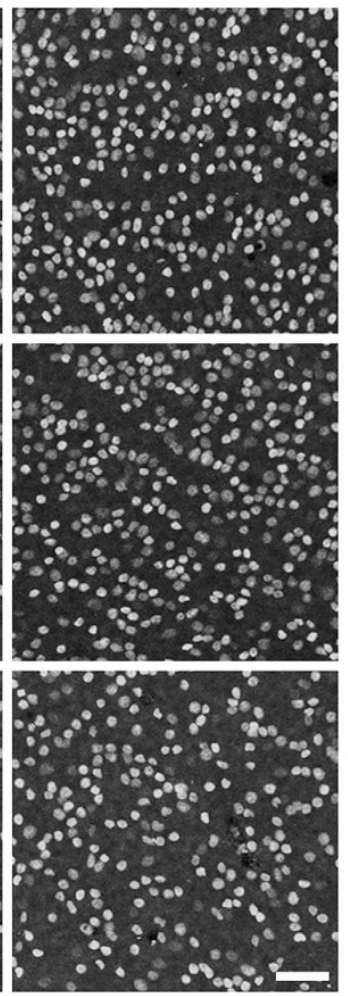

- Control-Vehicle

$\square$ Ischemia-Vehicle

$\square$ Ischemia-CsA

Control-CsA

Figure 2 CsA promotes RGC survival in ischemic retina. Vehicle or CsA treatment was begun daily until 1 day before the induction of transient retinal ischemia and continued for 2 weeks. (a) Brn3a whole-mount immunohistochemistry. High magnification showed representative images from the central, middle and peripheral area of retinas. (b) Quantitative analysis of RGC survival. Values are mean \pm S.D. ( $n=7$ retinas per group). ${ }^{*}$ Significant at $P<0.05$ compared with vehicle-treated non-ischemic contralateral control retina and ${ }^{* *}$ significant at $P<0.01$ compared with vehicle-treated ischemic retina. Scale bar, $50 \mu \mathrm{m}$ (all panels)

GCL compared with vehicle-treated non-ischemic control retina (Figure 5c). However, CsA treatment showed a partial preservation of $\mathrm{Bcl}-\mathrm{xL}$ immunoreactivity in RGCs of the GCL in ischemic retina (Figure $5 \mathrm{~d}$ ). In addition, we found that $\mathrm{Bcl}-2$ protein expression was not detected in vehicle-treated nonischemic control retina (Supplementary Figure 3), correlating with a previous study of the minimal expression of $\mathrm{Bcl}-2$ in the normal adult rat retina. ${ }^{34}$ Interestingly, however, $\mathrm{Bcl}-2$ protein expression was significantly induced in vehicletreated ischemic retina (Supplementary Figure 3). In contrast, CsA treatment significantly decreased $\mathrm{Bcl}-2$ protein expression in the ischemic retina compared with vehicletreated ischemic retina $(P<0.01$; Supplementary Figure 3$)$.

CsA preserves Tfam protein expression but does not alter mtDNA content in ischemic retina. To determine whether acute IOP elevation induces alteration of mtDNA in ischemic retina and whether CsA treatment preserves this alteration in ischemic retina, we performed western blot analysis using an antibody for Tfam and measured mtDNA content by real-time PCR analysis. We observed that Tfam protein expression was significantly increased by $1.28 \pm 0.05$-fold in ischemic retina at $12 \mathrm{~h} \quad(P<0.05$; Figure 6a). However, although CsA treatment preserved Tfam protein expression in ischemic retina at $12 \mathrm{~h}$ compared with vehicle-treated ischemic retina $(P<0.01$; Figure $6 a)$, surprisingly, we also found that there was a significant increase of Tfam protein expression by $1.63 \pm 0.07$-fold in CsA-treated non-ischemic control retina compared with vehicle-treated non-ischemic control retina $(P<0.01$; Figure 6a). Of interest, real-time PCR analysis showed that there were no statistically significant differences in mtDNA 
a

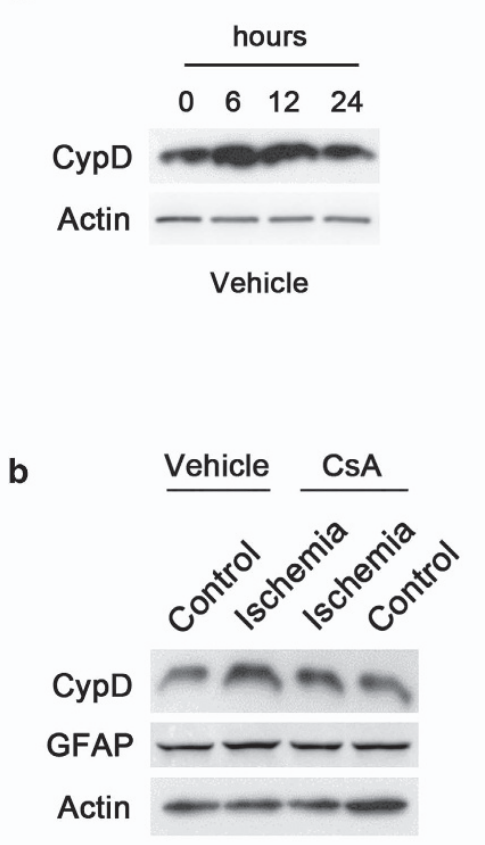

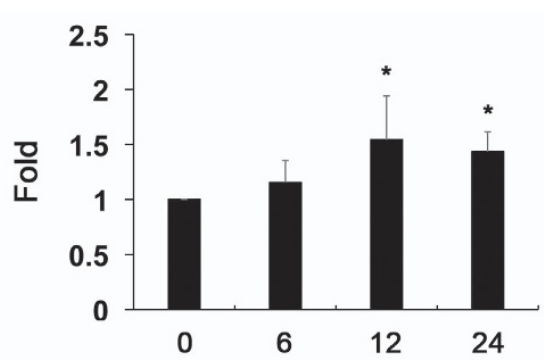

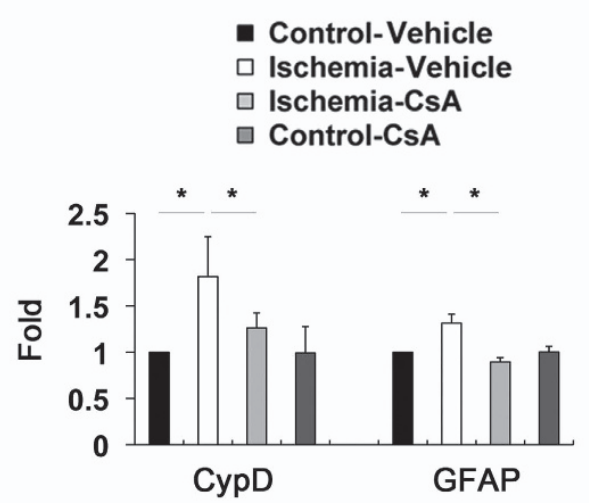

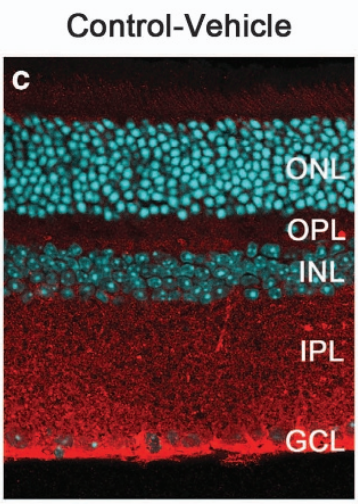
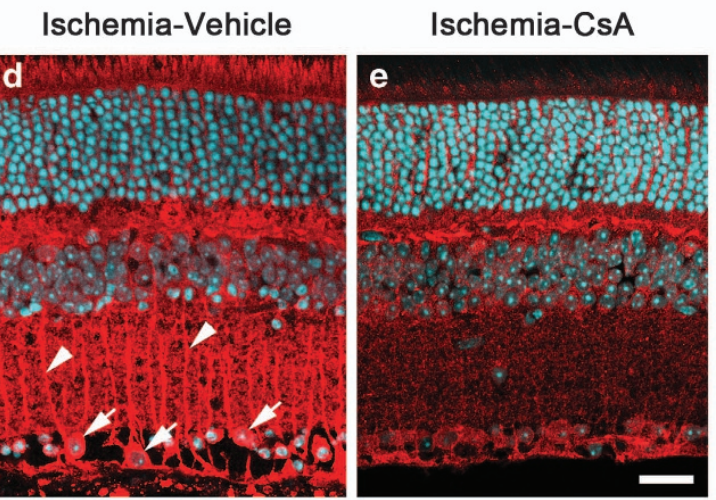

Figure 3 CsA prevents the upregulation of CypD and GFAP protein expression in ischemic retina. Vehicle or CsA treatment was begun daily until 1 day before the induction of transient retinal ischemia and continued for $12 \mathrm{~h}$. (a) Increase of CypD protein expression was maximal at $12 \mathrm{~h}$ in ischemic retina. The relative concentration of CypD protein expression was less at $24 \mathrm{~h}$ than at $12 \mathrm{~h}$ after ischemia-reperfusion. (b) CsA treatment preserved CypD and GFAP protein expression at $12 \mathrm{~h}$ compared with vehicle-treated ischemic retina. Values are mean \pm S.D. ( $n=4$ retinas per group). ${ }^{*}$ Significant at $P<0.05$ compared with vehicle-treated non-ischemic contralateral control retina or vehicle-treated ischemic retina. (c-e) CypD immunohistochemistry. In comparison with non-ischemic contralateral control retina (c), vehicle-treated ischemic retina showed increase of CypD immunoreactivity in the OPL, INL, IPL and GCL. Note that CypD immunoreactivity increased in Müller cells in the inner retina (arrowheads) as well as in RGCs in the GCL (arrows) (d). However, CsA treatment decreased CypD immunoreactivity in ischemic retina (e). Scale bar, $20 \mu \mathrm{m}$ (all panels)

content among the groups treated with vehicle or CsA in ischemic retina at $12 \mathrm{~h}$ (Figure $6 \mathrm{~b}$ ).

\section{Discussion}

Ischemic damage can trigger calcium dysregulation by increasing cellular calcium overload and induce pathological opening of MPTP, leading to the loss of the mitochondrial membrane potential. ${ }^{35-38}$ Collectively, these contribute to neuronal cell death pathway in ischemic injury of the CNS. ${ }^{37,39,40}$ As the molecular mechanisms underlying MPTP opening-mediated RGC death in ischemic retinal injury remain unknown, we observed for the first time direct evidence that acute IOP elevation-induced ischemic injury upregulates CypD protein expression in the retina. Moreover, inhibition of CypD by CsA treatment promotes RGC survival, blocks apoptotic cell death and preserves Tfam protein expression in ischemic retinal injury.

CypD is thought to be a key player to trigger calciummediated confirmation change in the ANT, leading to an opening of the MPTP in necrotic cell death. ${ }^{7,41}$ Mice that lack CypD not only ameliorate neuronal cell death against ischemia-reperfusion but also show a marked reduction in brain infarct size against acute middle cerebral artery occlusion-reperfusion $^{5,15,16}$ as well as protect both interneuron and motorneurons against excitotoxicity. ${ }^{42}$ In contrast, 
Control-Vehicle

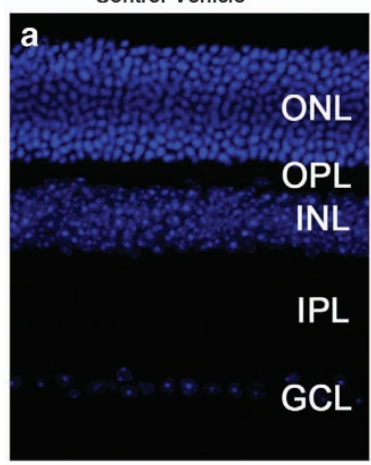

d

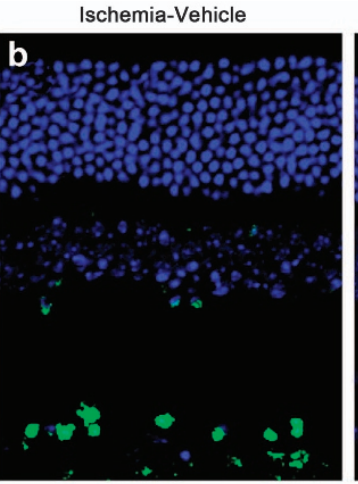

e
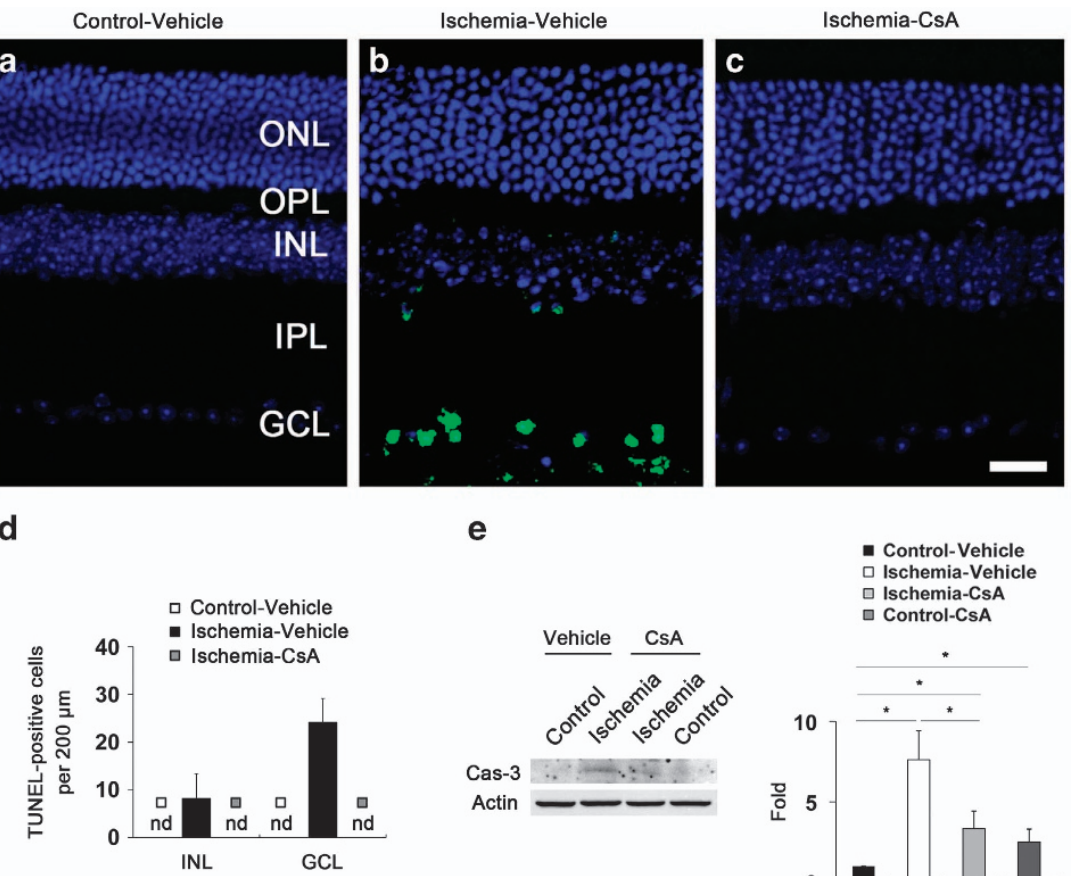

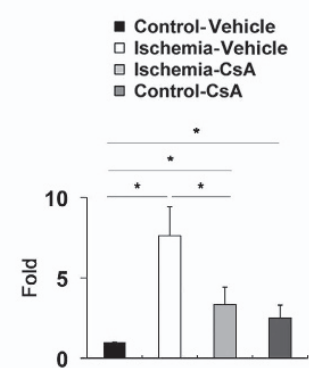

Figure 4 CsA blocks caspase-3 mediated apoptotic pathway in ischemic retina. Vehicle or CsA treatment was begun daily until 1 day before the induction of transient retinal ischemia and continued for $12 \mathrm{~h}$. (a) There were no TUNEL-positive cells in vehicle-treated non-ischemic contralateral control retina. (b) Ischemic retinas treated with vehicle showed TUNEL-positive apoptotic cell death in the GCL and INL at $12 \mathrm{~h}$. (c) In contrast, there were no TUNEL-positive cells in ischemic retina treated with CsA. (d) Quantitative analysis of TUNEL-positive cells. Values are mean \pm S.D. ( $n=8$ retinas per group). (e) Ischemic retinas showed a significant induction of cleaved caspase-3 protein expression at $12 \mathrm{~h}$. However, CsA treatment significantly reduced cleaved caspase-3 protein expression in ischemic retina at $12 \mathrm{~h}$ compared with vehicle-treated ischemic retina. Interestingly, CsA treatment also showed a significant induction of cleaved caspase-3 protein expression in non-ischemic contralateral control retina. Values are mean \pm S.D. ( $n=4$ retinas per group). * Significant at $P<0.05$ compared with vehicle-treated non-ischemic contralateral control retina or vehicle-treated ischemic retina. $\mathrm{ND}$, non-detectable. Scale bar, $20 \mu \mathrm{m}$ (all panels)

mice that overexpress CypD show mitochondrial swelling and spontaneous cell death. ${ }^{15,16}$ Furthermore, the high levels of CypD trigger greater vulnerability to MPT in neuronal mitochondria, ${ }^{17}$ as well as induce reduction of mitochondrial membrane potential and increase of ROS generation in focal cerebral ischemia. ${ }^{18}$ Taken together with these results, our findings suggest that the upregulation of CypD may facilitate an opening of the MPTP, increase mitochondrial vulnerability and trigger cell death in ischemic retina.

MPTP has been linked to glutamate excitotoxicity- or oxidative stress-mediated cell death pathway in ischemic injury of the CNS. ${ }^{7,15,42}$ Emerging evidence indicates that glutamate excitotoxicity and/or oxidative stress triggered mitochondrial dysfunction and apoptotic cell death in ischemic retinal injury. ${ }^{25}$ Therefore, it is possible that glutamate excitotoxicity and/or oxidative stress following acute IOP elevation may directly contribute to the upregulation of CypD protein expression and trigger the MPTP opening-mediated mitochondrial dysfunction in ischemic retina. Future studies will be needed to clarify the relationship between glutamate excitotoxicity/oxidative and CypD-mediated MPTP opening in ischemic retina.

CsA, the selective inhibitor of CypD, prevents MPTP by interacting with CypD and blocks calcium sensitivity. 27,43 Growing evidence indicates that CsA-mediated CypD inhibition ameliorates neuronal cell death or axon damage against brain ischemia or Wallerian degeneration in vivo, ${ }^{13,14,26,27,42}$ as well as against glucose and oxygen deprivation in vitro. ${ }^{44}$ In the current study, we found that CsA significantly prevented the upregulation of CypD and GFAP protein expression in ischemic retina. Intriguingly, CsA preserved CypD immunoreactivity in Müller cells of the inner retinal layer in ischemic retina. As retinal ischemia results in delayed neuronal cell death in the inner retinal layers, ${ }^{45}$ Müller cell activation in the inner retinal layers may have critical roles in neuroprotection and neurodegeneration in ischemic retinal injury. ${ }^{46-48}$ Although it is unclear whether ischemic insults such as excessive glutamate accumulation and oxidative stress induce the functional alteration of Müller cells, ${ }^{45,46}$ our findings reflect the possibility that ischemic insults may cause the upregulation of CypD and, in turn, trigger the dysfunction of Müller cells in ischemic retina, indicating that CsA may directly or indirectly modulate Müller glial reaction in the retina against ischemic injury.

Consistent with our result of CsA-mediated promotion on RGC survival in ischemic retina, we found that CsA preserved CypD protein expression in the GCL in ischemic retina at $12 \mathrm{~h}$. Interestingly, this result is highly correlated with CsAmediated protection against apoptotic cell death by reduction of cleaved caspase-3 protein expression in ischemic retina. As necrosis is one of important cell death pathways in ischemia-reperfusion injury similar to that in apoptosis, ${ }^{6,41}$ it has been reported that CypD-dependent MPTP opening by calcium overload and oxidative stress leads to necrosis rather 

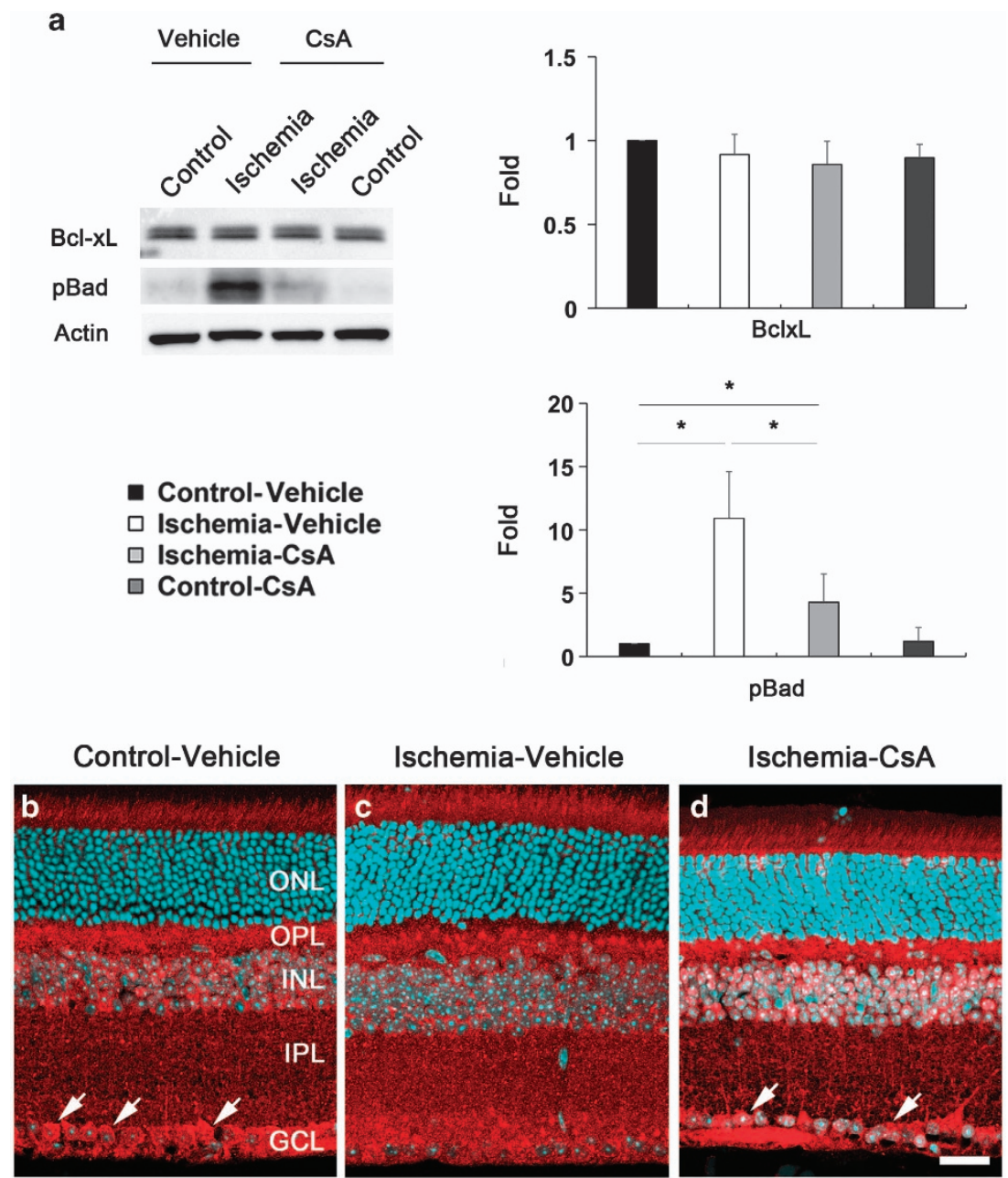

Figure $5 \mathrm{CsA}$ modulates $\mathrm{Bcl}-\mathrm{xL}$ and pBad protein expression in ischemic retina. Vehicle or CsA treatment was begun daily until 1 day before the induction of transient retinal ischemia and continued for $12 \mathrm{~h}$. (a) Vehicle-treated ischemic retina did not change Bcl-xL protein expression but significantly increased pBad protein expression in ischemic retina at $12 \mathrm{~h}$ compared with vehicle-treated non-ischemic contralateral control retina. However, CsA treatment significantly decreased pBad protein expression in ischemic retina, but there was no statistically significant difference in Bcl-xL protein expression at $12 \mathrm{~h}$ compared with vehicle-treated ischemic retina. Values are mean \pm S.D. ( $n=4$ retinas per group). ${ }^{*}$ Significant at $P<0.05$ compared with vehicle-treated non-ischemic contralateral control retina or vehicle-treated ischemic retina. (b-d) Bcl-xL immunohistochemistry. In vehicle-treated non-ischemic contralateral control retina, Bcl-xL immunoreactivity was localized in RGCs of the GCL (arrows) as well as in the OPL, INL and IPL. Interestingly, vehicle-treated ischemic retina showed less Bcl-xL immunoreactivity in RGCs of the GCL compared with non-ischemic control retina. However, CsA treatment showed a partial preservation of Bcl-xL immunoreactivity in RGCs of the GCL (arrows) in ischemic retina. Scale bar, $20 \mu \mathrm{m}$ (all panels)

than apoptosis. ${ }^{6,41}$ Nevertheless, the possible role of the MPTP opening in apoptotic cell death has been implicated in heart muscle cells in normal mice that have high levels of CypD $^{7,15}$ as well as in neurons exposed to moderate calcium overload. ${ }^{49-51}$ Taken together, our findings suggest that CypD-mediated MPTP opening may contribute to not only necrotic cell death but also to apoptotic cell death in ischemic retina injury. For further study of the links between CypDmediated MPTP opening, and apoptotic or necrotic pathway in ischemic retinal injury, it would be useful to investigate the cell death mechanisms in ischemic retina of CypD-deficient mice induced by acute IOP elevation.

$\mathrm{Bcl}-\mathrm{xL}$ regulates cell survival by promoting mitochondrial adenine-nucleotide exchange and prevents mitochondrial hyperpolarization by maintaining mitochondrial membrane permeability. ${ }^{52,53}$ In addition, activation of phosphatidyl inositol-3-kinase and protein kinase/Akt (Akt) pathway increases survival factors including $\mathrm{Bcl}-2$ and $\mathrm{Bcl}-\mathrm{xL} .{ }^{25,54}$ It has been reported that transient focal ischemic injury induced the downregulation of phosphorylated Akt (pAkt) in rat brain and CsA prevented this downregulation of $p A k t,{ }^{55}$ suggesting that CsA may trigger pAkt-mediated increase of $\mathrm{Bcl}-\mathrm{xL}$ in ischemic injury. More importantly, it has been demonstrated that $\mathrm{Bcl}-\mathrm{xL}$ was decreased in the adult retina after $\mathrm{ON}$ crush. ${ }^{34}$ In addition, Krajewski et al. ${ }^{56}$ reported that $\mathrm{Bcl}-\mathrm{xL}$ protein expression was decreased in neuronal cells following cerebral ischemic injury.

In the current study, interestingly, we found that the level of $\mathrm{Bcl}-\mathrm{xL}$ protein expression was not changed in the protein extracts from whole retinas following ischemia-reperfusion compared with control retinas. In addition, CsA did not show differences in $\mathrm{Bcl}-\mathrm{xL}$ protein expression among control and 
a

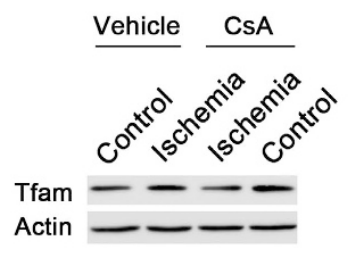

b

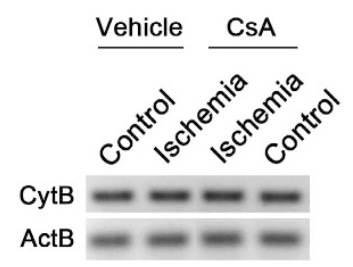

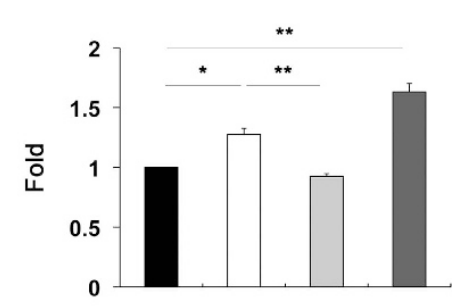

- Control-Vehicle 口 Ischemia-Vehicle $\square$ Control-CsA

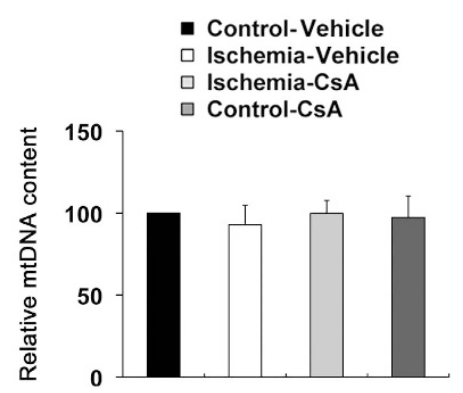
$\square$ Ischemia-CsA

Figure 6 CsA preserves Tfam protein expression but does not alter mtDNA content in ischemic retina. Vehicle or CsA treatment was begun daily until 1 day before the induction of transient retinal ischemia and continued for $12 \mathrm{~h}$. (a) In comparison with vehicle-treated non-ischemic contralateral control retina, Tfam protein expression was significantly increased in ischemic retina at $12 \mathrm{~h}$. However, CsA treatment preserved Tfam protein expression in ischemic retina compared with vehicle-treated ischemic retina. Interestingly, there was a significant increase of Tfam protein expression in CsA-treated non-ischemic contralateral control retina compared with vehicle-treated non-ischemic contralateral control retina. Values are mean \pm S.D. ( $n=4$ retinas per group). *Significant at $P<0.05$ compared with vehicle-treated non-ischemic contralateral control retina treated and ${ }^{* *}$ significant at $P<0.01$ compared with vehicle-treated non-ischemic contralateral control retina treated or vehicle-treated ischemic retina. (b) mtDNA content measurement. There were no statistically significant differences in mtDNA content in ischemic retina among control and ischemic groups treated with vehicle or CsA

ischemic retinal groups. Surprisingly, however, we observed that ischemic retina showed less $\mathrm{Bcl}-\mathrm{xL}$ immunoreactivity in RGCs of the GCL. Furthermore, CsA partially preserved Bcl$\mathrm{xL}$ immunoreactivity in RGCs against ischemic injury. On the basis of these results, our findings suggest that $\mathrm{Bcl}-\mathrm{xL}$ is the predominant member of $\mathrm{Bcl}-2$ family in rodent retina. ${ }^{34}$ Furthermore, it is possible that CsA rescues RGCs by restoring $\mathrm{Bcl}-\mathrm{xL}$ protein expression against ischemic injury. The increase of $\mathrm{pBad}$ protein expression has been thought as an endogenous compensatory mechanism to promote cell survival against ischemic brain or retinal injury. ${ }^{25,57}$ Our recent study have demonstrated that ischemic injury significantly triggered the increase of pBad protein expression in rat retina. $^{25}$ In a good agreement with this result, we also observed that ischemic injury significantly increased pBad protein expression in mouse retina. However, CsA highly preserved pBad protein expression in ischemic retina, suggesting that increasing pBad expression may be an important endogenous defense mechanism and that CsA may directly or indirectly modulate pBad-mediated signaling pathway in the retina against ischemic injury. Collectively, our

results indicate that CsA may protect RGCs against ischemic damage by preserving $\mathrm{Bcl}-\mathrm{xL}$ and $\mathrm{pBad}$ protein expression.

Ischemic injury-induced mitochondrial dysfunction includes induction of ROS generation, as well as alterations of mtDNA content and Tfam protein expression in the CNS. ${ }^{23,58}$ Recently, we have reported that acute IOP elevation-induced ischemic injury significantly increased Tfam protein expression in the retina and that blockade of glutamate excitotoxicity-induced oxidative stress by brimonidine treatment preserved Tfam protein expression in ischemic retina, suggesting that the preservation of Tfam may exert an endogenous repair mechanism for protecting RGCs against mitochondrial dysfunction induced by glutamate excitotoxicity and/or oxidative stress in ischemic retina. $^{25}$ In the current study, we observed that CsA preserved Tfam protein expression in ischemic retina at $12 \mathrm{~h}$. Tfam is rapidly increased in the early neurodegenerative events of neonatal hypoxic-ischemic brain injury. ${ }^{23}$ In contrast, mice lacking Tfam triggered impairment of mtDNA transcription and loss of mtDNA. ${ }^{19}$ Collectively, our findings suggest that CsA might preserve Tfam protein expression and ameliorate mitochondrial dysfunction by blocking CypDdependent MPTP opening against ischemic injury. In addition, we also found a significant increase of Tfam protein expression in CsA-treated non-ischemic control retina. As CsA interacts with CypD and therefore inhibits the MPTP and decreases calcium sensitivity, ${ }^{26,27}$ it is possible that increasing CsA might alter normal mitochondrial function and trigger the upregulation of Tfam protein expression in control retina. However, we cannot exclude the possibility that healthy neurons might be more sensitive and resistant by increasing Tfam expression in response to CsA-mediated mitochondrial stress that may cause any adverse effect in normal retina compared with injured neurons in ischemic retina. Future studies will be needed to clarify this by examining the functional role of CsA-mediated Tfam expression in normal retina.

Interestingly, we found that there were no statistically significant differences in mtDNA content among control and ischemic groups. Because it has been reported that ischemic injury triggered reduction of mtDNA content in focal cerebral ischemia-reperfusion or that hypoxicischemic injury induced increase of mtDNA content in rat brain, ${ }^{23,58}$ our findings reflect the possibility that increasing Tfam protein expression may prevent alteration of mtDNA content in ischemic retina. As overexpression of Tfam delayed neuronal cell death following transient forebrain ischemia in mice, ${ }^{22,24}$ we believe that studying the benefit of increased Tfam expression on mitochondrial dysfunction including mtDNA alteration may provide a therapeutic target for fighting against RGC degeneration in ischemic retinal injury.

In conclusion, these results provide direct evidence that activation of CypD-mediated MPTP opening is associated with apoptotic pathway and mitochondrial alteration in RGC death of ischemic retinal injury. On the basis of these observations, our findings suggest that CsA-mediated CypD inhibition may provide a promising therapeutic potential for protecting RGCs against ischemic injury-mediated mitochondrial dysfunction. 


\section{Materials and Methods}

Animals. Female, 4-month-old C57BL/6 mice (20-25 g in weight; The Jackson Laboratories, Bar Harbor, ME, USA) were housed in covered cages, fed with a standard rodent diet ad libitum and kept on a $12 \mathrm{~h}$ light/12 $\mathrm{h}$ dark cycle. All procedures concerning animals were performed in accordance with the ARVO statement for the Use of Animals in Ophthalmic and Vision Research and under protocols approved by institutional IACUC committees at the University of California San Diego.

Induction of transient retinal ischemia. The mice were anesthetized with a mixture of ketamine $(100 \mathrm{mg} / \mathrm{kg}$, Ketaset; Fort Dodge Animal Health, Fort Dodge, IA, USA) and xylazine $(9 \mathrm{mg} / \mathrm{kg}$, TranquiVed; Vedeco $\mathrm{Inc}$., St. Joseph, MO, USA) by intraperitoneal injection. Eyes were also treated with $1 \%$ proparacaine drops. A $30-G$ needle was inserted into the anterior chamber of right eye that was connected by flexible tubing to a saline reservoir. By raising the reservoir, IOP was elevated to $70-90 \mathrm{~mm} \mathrm{Hg}$ for $50 \mathrm{~min}$. Sham treatment was performed in the contralateral eyes by the insertion of a needle in the anterior chamber without saline injection. Retinal ischemia was confirmed by observing whitening of the iris and loss of the retina red reflex. ${ }^{25,59}$ IOP was measured with a tonometer (TonoLab; Tiolatoy, Helsinki, Finland) during ischemia. Non-ischemic contralateral control retinas were used as control.

Pharmacological treatment. CsA was provided from Allergan (Irvine, CA USA) and phosphate-buffered saline (PBS)/EtOH was used as vehicle control. Both CsA and vehicle were injected once by intraperitoneal injection at $24 \mathrm{~h}$ before and at the time of initial IOP elevation for short-term experiments, as well as treated daily by intraperitoneal injection for 2 weeks to examine RGC survival. Four groups were studied: a group of non-ischemic $\mathrm{C} 57 \mathrm{BL} / 6$ mice treated with vehicle (PBS/EtOH, $n=30$ mice), a group of ischemic $\mathrm{C} 57 \mathrm{BL} / 6$ mice treated with vehicle ( $n=30$ mice), a group of non-ischemic C57BL/6 mice treated with CsA ( $5 \mathrm{mg} / \mathrm{kg}$ per day, $n=30$ mice) and a group of ischemic C57BL/6 mice treated with $\operatorname{CsA}(n=30$ mice)

Tissue preparation. Six to $24 \mathrm{~h}$ after acute IOP elevation, light-adapted mice were anesthetized with intraperitoneal injection of a mixture of ketamine/xylazine, as described, and then mice were perfused transcardially with $0.9 \%$ saline followed by $4 \%$ paraformaldehyde in $1 \times \mathrm{PBS}(\mathrm{pH} 7.4)$. Both eyes were enucleated and fixed in $4 \%$ paraformaldehyde in PBS for $4 \mathrm{~h}$ at $4{ }^{\circ} \mathrm{C}$. After several washes in PBS, the retinas were dissected and then dehydrated through graded ethanol solutions and embedded in polyester wax.

Whole-mount immunohistochemical analysis. Retinas from enucleated eyes were dissected as flattened whole mounts at 2 weeks after ischemia. Retinas were immersed in PBS containing $30 \%$ sucrose for $24 \mathrm{~h}$ at $4{ }^{\circ} \mathrm{C}$. The retinas were blocked in PBS containing $3 \%$ donkey serum, $1 \%$ bovine serum albumin, $1 \%$ fish gel and $0.1 \%$ Triton $\mathrm{X}-100$ for $1 \mathrm{~h}$, and then incubated with goat polyclonal anti-Brn3a antibody (1:500; Santa Cruz Biotechnology, Santa Cruz, $\mathrm{CA}$, USA) for 3 days at $4^{\circ} \mathrm{C}$. After several wash steps, the retinas were incubated with the secondary antibodies, Alexa Fluor-568 donkey anti-goat IgG antibody (Invitrogen, Carlsbad, CA, USA) for $24 \mathrm{~h}$, and subsequently washed with PBS. The retinas were counterstained with the nucleic acid stain Hoechst $33342(1 \mu \mathrm{g} / \mathrm{ml}$; Invitrogen) in PBS. Images were captured with a spinning-disc confocal microscope (Olympus America Inc., Center Valley, PA USA) equipped with a high-precision closed loop XY stage and closed loop Z control with commercial mosaic acquisition software (MicroBrightField; MBF Bioscience Inc., Williston, VT, USA). The microscope is equipped with high-resolution high-sensitive CCD camera for high-speed mosaic acquisition.

Quantitative analysis for RGC counting. To count RGCs labeled with Brn3a, each retinal quadrant was divided into three zones by central, middle and peripheral retina (one-sixth $(\sim 400 \mu \mathrm{m})$, three-sixths $(\sim 1200 \mu \mathrm{m})$ and five-sixths $(\sim 2000 \mu \mathrm{m})$ of the retinal radius from the $\mathrm{ON}$ head). Images were taken at $\times 20$, covering an area of $0.344 \mathrm{~mm}^{2}$, and then the number of RGCs was normalized per $\mathrm{mm}^{2}$. RGC densities were measured in 24 distinct areas (two areas at central, middle and peripheral per retinal quadrant) per condition by two investigators in a masked manner, and the scores were averaged ( $n=7$ retinas per group). RGC densities were automatically measured using the ImageJ cell counting analysis (http://rsb.info.nih.gov/ij/; National Institute of Health, Bethesda, MD, USA).
Immunohistochemical analysis. Immunohistochemical staining of retinal cross-sections at $12 \mathrm{~h}$ after transient ischemia was performed. Five sections per wax block from each group were used for immunohistochemical analysis. Primary antibodies were mouse monoclonal anti-CypD antibody (1:100; Life Technologies, Grand Island, NY, USA) and rabbit polyclonal anti-Bcl-xL antibody (1:1000; Cell Signaling, Danvers, MA, USA). To prevent nonspecific background, tissues were incubated in 1\% bovine serum albumin/PBS for $1 \mathrm{~h}$ at room temperature before incubation with the primary antibodies for $16 \mathrm{~h}$ at $4{ }^{\circ} \mathrm{C}$. After several wash steps, the tissues were incubated with the secondary antibodies, Alexa Fluor 568 dye-conjugated donkey anti-rabbit lgG antibody (1:100; Invitrogen) for $4 \mathrm{~h}$ at $4{ }^{\circ} \mathrm{C}$, and subsequently washed with PBS. The sections were counterstained with the nucleic acid stain Hoechst 33342 (Invitrogen) in PBS. Images were acquired with confocal microscopy (Olympus FluoView1000; Olympus, Tokyo, Japan).

Western blot analysis. Following 6,12 or $24 \mathrm{~h}$ after transient ischemia, the retinas were homogenized in a glass-Teflon Potter homogenizer in RIPA lysis buffer ( $150 \mathrm{mM} \mathrm{NaCl}, 1 \mathrm{mM}$ EDTA, $1 \%$ NP-40, 0.1\% SDS, $1 \mathrm{mM}$ DTT, $0.5 \%$ sodium deoxycholate and $50 \mathrm{mM}$ Tris- $\mathrm{Cl}, \mathrm{pH} 7.6$ ) containing complete protease inhibitors (Roche Biochemicals, Indianapolis, IN). Each sample $(10 \mu \mathrm{g} ; n=4$ retinas per group) was separated by SDS-PAGE and electrotransferred to polyvinylidenedifluoride membrane. The membrane was blocked with $5 \%$ non-fat dry milk and $0.1 \%$ Tween-20 in PBS for $1 \mathrm{~h}$, incubated with mouse monoclonal anti-GFAP $(1: 3000$; Sigma, St. Louis, MO, USA), mouse monoclonal anti-CypD antibody (1:1000; Life Technologies), rabbit polyclonal anti-Bax antibody (1:500; Santa Cruz Biotechnology), rabbit polyclonal anti-Bcl-xL antibody (1:1000; Cell Signaling), mouse monoclonal anti-pBad (1:2000; Cell Signaling), mouse monoclonal caspase-3 antibody $(1: 3000$; Cell Signaling), rabbit polyclonal anti-Tfam antibody $(1: 3000$; GeneTex, Irvine, CA, USA) and mouse monoclonal anti-actin antibody (1:10000; Millipore, Billerica, MA, USA) for overnight at $4{ }^{\circ} \mathrm{C}$. After several washes in Tween/PBS, the membranes were incubated with peroxidaseconjugated goat anti-mouse IgG (1:5000; Bio-Rad, Hercules, CA, USA), goat anti-rabbit IgG (1:5000; Bio-Rad) or goat anti-mouse IgG (1:5000; Bio-Rad), and developed using chemiluminescence detection (ECL Plus; GE Healthcare Bio-Science, Piscataway, NJ, USA). The scanned film images were analyzed by ImageJ (National Institute of Health) and band densities were normalized to the band densities for actin.

TUNEL staining. The retinal cross-sections prepared at $12 \mathrm{~h}$ after transient ischemia were incubated with proteinase $\mathrm{K}(10 \mu \mathrm{g} / \mathrm{ml}, 10 \mathrm{mM}$ Tris, $\mathrm{pH}$ 7.4-8.0) for $10 \mathrm{~min}$ at $37^{\circ} \mathrm{C}$. After rinsing in PBS, the sections were incubated with terminal deoxynucleotidyl transferase plus nucleotide mixture in reaction buffer for $60 \mathrm{~min}$ at $37^{\circ} \mathrm{C}$ (In situ Cell Death Detection Kit; Roche Applied Science, Indianapolis, IN, USA) as described previously. ${ }^{60}$ To count TUNEL-positive cells, the area was divided into three layers by GCL, INL and outer nuclear layer (ONL). TUNELpositive cells were counted in eight microscopic fields of $0.2 \mathrm{~mm}$ from retinal sections per condition ( $n=5$ retinas) by two investigators in a masked manner, and the scores were averaged.

Measurement of mitochondrial DNA content. Mitochondrial DNA (mtDNA) content of each sample at $12 \mathrm{~h}$ after transient ischemia was determined. Briefly, total genomic DNA was isolated from retinas by using DNeasy Blood \& Tissue Kit (Qiagen, Valencia, CA, USA) as described in the manufacturer's protocol. For the measurement of mtDNA content, PCR was performed using total genomic DNA and mitochondrial cytochrome $B$ (CytB - F: $5^{\prime}$-GGTCTTTTCTTAGC CATACACTACA-3'; CytB - R: $5^{\prime}$-ATATCGGATTAGTCACCCGTAAT-3') or $\beta$-actin (ActB - F; GATCGATGCCGGTGCTAAGA-3'; ActB - R: 5'-CACCATCACACCCT GTGGAAG- $3^{\prime}$ ) primers. PCR products were electrophoresed on a $2 \%$ agarose gel and visualized by ethidium bromide. For the quantification of the relative mtDNA content of each group, real-time PCR was carried out using MX3000P real-time PCR system (Stratagene, La Jolla, CA, USA) as follows. Total genomic DNAs $(10 \mathrm{ng})$ from each sample were amplified using IQTM SYBR Green supermix (Bio-Rad) and CytB or ActB primers for 40 cycles (initial incubation at $95^{\circ} \mathrm{C}$ for $10 \mathrm{~min}$, and 40 cycles $\left(95^{\circ} \mathrm{C}\right.$ for $30 \mathrm{~s}, 55^{\circ} \mathrm{C}$ for $30 \mathrm{~s}$ and $72^{\circ} \mathrm{C}$ for $\left.20 \mathrm{~s}\right)$ ). Output data were obtained as $\mathrm{Ct}$ values and the difference of mtDNA content among samples was calculated using the comparative $\mathrm{Ct}$ method. $A c t B$ gene was used to normalize the ratio between mtDNA and genomic DNA. The samples were run in triplicates for all experiments. 
Statistical analysis. Data were presented as the mean \pm S.D. Comparison of two or three experimental conditions was evaluated using the unpaired, twotailed Student's $t$-test or one-way analysis of variance and the Bonferroni $t$-test. $P<0.05$ was considered to be statistically significant.

\section{Conflict of Interest}

Dr. Ju received funding from Allergan Inc. for these studies. Dr. Wheeler was employed by Allergan Inc. during these studies. Dr. Weinreb is a consultant for Allergan Inc. SY Kim, Dr. Shim and Dr. Kim declare no potential conflict of interest.

Acknowledgements. This work was supported, in part, by funding provided by an Allergan Inc. (WKJ), the National Institute Health Grants EY018658 (WKJ) and P30EY022589 (Vision Research Core Grant) and an unrestricted grant from Research to Prevent Blindness (New York, NY, USA).

1. Weinreb RN, Khaw PT. Primary open-angle glaucoma. Lancet 2004; 363: 1711-1720.

2. Matsumoto S, Friberg H, Ferrand-Drake M, Wieloch T. Blockade of the mitochondrial permeability transition pore diminishes infarct size in the rat after transient middle cerebral artery occlusion. J Cereb Blood Flow Metab 1999; 19: 736-741.

3. Russo R, Cavaliere F, Rombola L, Gliozzi M, Cerulli A, Nucci C et al. Rational basis for the development of coenzyme Q10 as a neurotherapeutic agent for retinal protection. Prog Brain Res 2008; 173: 575-582.

4. Leger PL, De Paulis D, Branco S, Bonnin P, Couture-Lepetit E, Baud O et al. Evaluation of cyclosporine A in a stroke model in the immature rat brain. Exp Neurol 2011; 230: 58-66.

5. Schinzel AC, Takeuchi O, Huang Z, Fisher JK, Zhou Z, Rubens J et al. Cyclophilin D is a component of mitochondrial permeability transition and mediates neuronal cell death after focal cerebral ischemia. Proc Natl Acad Sci USA 2005; 102: 12005-12010.

6. Tsujimoto Y, Shimizu S. Role of the mitochondrial membrane permeability transition in cell death. Apoptosis 2007; 12: 835-840.

7. Halestrap A. Biochemistry: a pore way to die. Nature 2005; 434: 578-579.

8. Nucci C, Tartaglione R, Cerulli A, Mancino R, Spano A, Cavaliere F et al. Retinal damage caused by high intraocular pressure-induced transient ischemia is prevented by coenzyme Q10 in rat. Int Rev Neurobiol 2007; 82: 397-406.

9. Crompton M, Virji S, Ward JM. Cyclophilin-D binds strongly to complexes of the voltage-dependent anion channel and the adenine nucleotide translocase to form the permeability transition pore. Eur J Biochem 1998; 258: 729-735.

10. Woodfield K, Ruck A, Brdiczka D, Halestrap AP. Direct demonstration of a specific interaction between cyclophilin-D and the adenine nucleotide translocase confirms their role in the mitochondrial permeability transition. Biochem J 1998; 336(Part 2): 287-290.

11. Kokoszka JE, Waymire KG, Levy SE, Sligh JE, Cai J, Jones DP et al. The ADP/ATP translocator is not essential for the mitochondrial permeability transition pore. Nature 2004; 427: $461-465$.

12. Javadov S, Karmazyn M. Mitochondrial permeability transition pore opening as an endpoint to initiate cell death and as a putative target for cardioprotection. Cell Physiol Biochem 2007; 20: 1-22.

13. Rao VK, Carlson EA, Yan SS. Mitochondrial permeability transition pore is a potential drug target for neurodegeneration. Biochim Biophys Acta 2013; e-pub ahead of print 18 September 2013; doi:10.1016/j.bbadis.2013.09.003.

14. Barrientos SA, Martinez NW, Yoo S, Jara JS, Zamorano S, Hetz $\mathrm{C}$ et al. Axonal degeneration is mediated by the mitochondrial permeability transition pore. $J$ Neurosci 2011; 31: 966-978.

15. Baines CP, Kaiser RA, Purcell NH, Blair NS, Osinska H, Hambleton MA et al. Loss of cyclophilin $D$ reveals a critical role for mitochondrial permeability transition in cell death. Nature 2005; 434: 658-662.

16. Nakagawa T, Shimizu S, Watanabe T, Yamaguchi O, Otsu K, Yamagata H et al. Cyclophilin D-dependent mitochondrial permeability transition regulates some necrotic but not apoptotic cell death. Nature 2005; 434: 652-658.

17. Naga KK, Sullivan PG, Geddes JW. High cyclophilin D content of synaptic mitochondria results in increased vulnerability to permeability transition. J Neurosci 2007; 27: 7469-7475.

18. Li J, Ma X, Yu W, Lou Z, Mu D, Wang Y et al. Reperfusion promotes mitochondrial dysfunction following focal cerebral ischemia in rats. PLOS One 2012; 7: e46498.

19. Larsson NG, Wang J, Wilhelmsson $H$, Oldfors A, Rustin P, Lewandoski $M$ et al. Mitochondrial transcription factor $A$ is necessary for mtDNA maintenance and embryogenesis in mice. Nat Genet 1998; 18: 231-236.

20. Falkenberg M, Larsson NG, Gustafsson CM. DNA replication and transcription in mammalian mitochondria. Annu Rev Biochem 2007; 76: 679-699.

21. Ngo HB, Kaiser JT, Chan DC. The mitochondrial transcription and packaging factor Tfam imposes a U-turn on mitochondrial DNA. Nat Struct Mol Biol 2011; 18: 1290-1296.

22. Hokari M, Kuroda S, Kinugawa S, Ide T, Tsutsui H, Iwasaki Y. Overexpression of mitochondrial transcription factor A (TFAM) ameliorates delayed neuronal death due to transient forebrain ischemia in mice. Neuropathology 2010; 30: 401-407.
23. Yin W, Signore AP, Iwai M, Cao G, Gao Y, Chen J. Rapidly increased neuronal mitochondrial biogenesis after hypoxic-ischemic brain injury. Stroke 2008; 39: 3057-3063.

24. Piao Y, Kim HG, Oh MS, Pak YK. Overexpression of TFAM, NRF-1 and myr-AKT protects the MPP $(+)$-induced mitochondrial dysfunctions in neuronal cells. Biochim Biophys Acta 2012; 1820: 577-585.

25. Lee D, Kim KY, Noh YH, Chai S, Lindsey JD, Ellisman MH et al. Brimonidine blocks glutamate excitotoxicity-induced oxidative stress and preserves mitochondrial transcription factor a in ischemic retinal injury. PLOS One 2012; 7: e47098.

26. Uchino H, Hatakeyama K, Morota S, Tanoue T, Nishiyama T, Usui D et al. Cyclophilin-D inhibition in neuroprotection: dawn of a new era of mitochondrial medicine. Acta Neurochir Supp/ 2013; 118: 311-315.

27. Friberg H, Ferrand-Drake M, Bengtsson F, Halestrap AP, Wieloch T. Cyclosporin A, but not FK 506, protects mitochondria and neurons against hypoglycemic damage and implicates the mitochondrial permeability transition in cell death. J Neurosci 1998; 18: 5151-5159.

28. Shiga Y, Onodera H, Matsuo Y, Kogure K. Cyclosporin A protects against ischemiareperfusion injury in the brain. Brain Res 1992; 595: 145-148.

29. Li PA, Kristian T, He QP, Siesjo BK. Cyclosporin A enhances survival, ameliorates brain damage, and prevents secondary mitochondrial dysfunction after a 30-minute period of transient cerebral ischemia. Exp Neurol 2000; 165: 153-163.

30. Yuen CM, Sun CK, Lin YC, Chang LT, Kao YH, Yen CH et al. Combination of cyclosporine and erythropoietin improves brain infarct size and neurological function in rats after ischemic stroke. J Transl Med 2011; 9: 141.

31. Okonkwo DO, Povlishock JT. An intrathecal bolus of cyclosporin A before injury preserves mitochondrial integrity and attenuates axonal disruption in traumatic brain injury. J Cereb Blood Flow Metab 1999; 19: 443-451.

32. Sullivan PG, Thompson MB, Scheff SW. Cyclosporin A attenuates acute mitochondrial dysfunction following traumatic brain injury. Exp Neurol 1999; 160: 226-234.

33. Cui Q, Hodgetts SI, Hu Y, Luo JM, Harvey AR. Strain-specific differences in the effects of cyclosporin A and FK506 on the survival and regeneration of axotomized retinal ganglion cells in adult rats. Neuroscience 2007; 146: 986-999.

34. Levin LA, Schlamp CL, Spieldoch RL, Geszvain KM, Nickells RW. Identification of the bcl-2 family of genes in the rat retina. Invest Ophthalmol Vis Sci 1997; 38: 2545-2553.

35. Friberg $\mathrm{H}$, Wieloch $\mathrm{T}$. Mitochondrial permeability transition in acute neurodegeneration. Biochimie 2002; 84: 241-250.

36. Javadov S, Kuznetsov A. Mitochondrial permeability transition and cell death: the role of cyclophilin d. Front Physiol 2013; 4: 76.

37. Christophe M, Nicolas S. Mitochondria: a target for neuroprotective interventions in cerebral ischemia-reperfusion. Curr Pharm Des 2006; 12: 739-757.

38. Gouriou Y, Demaurex N, Bijlenga P, De Marchi U. Mitochondrial calcium handling during ischemia-induced cell death in neurons. Biochimie 2011; 93: 2060-2067.

39. Blomgren $\mathrm{K}$, Zhu C, Hallin U, Hagberg H. Mitochondria and ischemic reperfusion damage in the adult and in the developing brain. Biochem Biophys Res Commun 2003; 304: 551-559.

40. Mazzeo AT, Beat A, Singh A, Bullock MR. The role of mitochondrial transition pore, and its modulation, in traumatic brain injury and delayed neurodegeneration after TBI. Exp Neurol 2009; 218: 363-370.

41. Linkermann A, Brasen JH, Darding M, Jin MK, Sanz AB, Heller JO et al. Two independent pathways of regulated necrosis mediate ischemia-reperfusion injury. Proc Natl Acad Sci USA 2013; 110: 12024-12029.

42. Martin LJ. An approach to experimental synaptic pathology using green fluorescent protein-transgenic mice and gene knockout mice to show mitochondrial permeability transition pore-driven excitotoxicity in interneurons and motoneurons. Toxicol Pathol 2011; 39: 220-233.

43. Connern CP, Halestrap AP. Recruitment of mitochondrial cyclophilin to the mitochondrial inner membrane under conditions of oxidative stress that enhance the opening of a calcium-sensitive non-specific channel. Biochem J 1994; 302(Part 2): 321-324.

44. Malouitre S, Dube H, Selwood D, Crompton M. Mitochondrial targeting of cyclosporin A enables selective inhibition of cyclophilin-D and enhanced cytoprotection after glucose and oxygen deprivation. Biochem J 2010; 425: 137-148.

45. Ju WK, Kim KY, Hofmann HD, Kim IB, Lee MY, Oh SJ et al. Selective neuronal survival and upregulation of PCNA in the rat inner retina following transient ischemia. J Neuropathol Exp Neurol 2000; 59: 241-250.

46. Bringmann A, Pannicke T, Grosche J, Francke M, Wiedemann P, Skatchkov SN et al. Muller cells in the healthy and diseased retina. Prog Retin Eye Res 2006; 25: 397-424.

47. Ju WK, Lee MY, Hofmann HD, Kirsch M, Oh SJ, Chung JW et al. Increased expression of ciliary neurotrophic factor receptor alpha mRNA in the ischemic rat retina. Neurosci Lett 2000; 283: 133-136.

48. Wurm A, Pannicke T, landiev I, Francke M, Hollborn M, Wiedemann P et al. Purinergic signaling involved in Muller cell function in the mammalian retina. Prog Retin Eye Res 2011; 30: 324-342.

49. Crompton M. The mitochondrial permeability transition pore and its role in cell death. Biochem J 1999; 341(Part 2): 233-249.

50. Ankarcrona M, Dypbukt JM, Bonfoco E, Zhivotovsky B, Orrenius S, Lipton SA et al. Glutamate-induced neuronal death: a succession of necrosis or apoptosis depending on mitochondrial function. Neuron 1995; 15: 961-973.

51. Bonfoco E, Krainc D, Ankarcrona M, Nicotera P, Lipton SA. Apoptosis and necrosis: two distinct events induced, respectively, by mild and intense insults with $N$-methyl-D-aspartate or nitric oxide/superoxide in cortical cell cultures. Proc Natl Acad Sci USA 1995; 92: 7162-7166. 
52. Vander Heiden MG, Chandel NS, Schumacker PT, Thompson CB. Bcl-xL prevents cell death following growth factor withdrawal by facilitating mitochondrial ATP/ADP exchange. Mol Cell 1999; 3: 159-167.

53. Vander Heiden MG, Thompson CB. Bcl-2 proteins: regulators of apoptosis or of mitochondrial homeostasis? Nat Cell Biol 1999; 1: E209-E216.

54. Lai RK, Chun T, Hasson D, Lee S, Mehrbod F, Wheeler L. Alpha-2 adrenoceptor agonist protects retinal function after acute retinal ischemic injury in the rat. Vis Neurosci 2002; 19: 175-185.

55. Yoshimoto T, Uchino H, He QP, Li PA, Siesjo BK. Cyclosporin A, but not FK506, prevents the downregulation of phosphorylated Akt after transient focal ischemia in the rat. Brain Res 2001; 899: 148-158.

56. Krajewski S, Blomqvist C, Franssila K, Krajewska M, Wasenius VM, Niskanen E et al. Reduced expression of proapoptotic gene BAX is associated with poor response rates to combination chemotherapy and shorter survival in women with metastatic breast adenocarcinoma. Cancer Res 1995; 55: 4471-4478.

57. Uchino H, Minamikawa-Tachino R, Kristian T, Perkins G, Narazaki M, Siesjo BK et al Differential neuroprotection by cyclosporin A and FK506 following ischemia corresponds with differing abilities to inhibit calcineurin and the mitochondrial permeability transition. Neurobiol Dis 2002; 10: 219-233.

58. Chen $\mathrm{H}, \mathrm{Hu} \mathrm{CJ}, \mathrm{He}$ YY, Yang DI, Xu J, Hsu CY. Reduction and restoration of mitochondrial dna content after focal cerebral ischemia/reperfusion. Stroke 2001; 32: 2382-2387.

59. Ju WK, Kim KY. Measuring glutamate receptor activation-induced apoptotic cell death in ischemic rat retina using the TUNEL assay. Methods Mol Biol 2011; 740: 149-156.

60. Park SW, Kim KY, Lindsey JD, Dai Y, Heo H, Nguyen DH et al. A selective inhibitor of drp1, mdivi-1, increases retinal ganglion cell survival in acute ischemic mouse retina. Invest Ophthalmol Vis Sci 2011; 52: 2837-2843.

(c) $\odot$ Cell Death and Disease is an open-access journal published by Nature Publishing Group. This work is licensed under a Creative Commons Attribution-NonCommercialNoDerivs 3.0 Unported License. To view a copy of this license, visit http://creativecommons.org/licenses/by-nc-nd/3.0/

Supplementary Information accompanies this paper on Cell Death and Disease website (http://www.nature.com/cddis) 